\title{
1 EFFECTS OF SELECTED AMINO ACIDS AND WATER-SOLUBLE \\ 2 VITAMINS ON ACRYLAMIDE FORMATION IN A RIPE OLIVE MODEL \\ 3 SYSTEM
}

4

5

6 Antonio López-López, Víctor Manuel Beato, Antonio Higinio Sánchez, Pedro García-

7 García, Alfredo Montaño*

8

9 Food Biotechnology Department, Instituto de la Grasa IG-CSIC, Avenida Padre García

10 Tejero 4, 41012 Seville, Spain

11 *Tel: +34 95 4691054, fax: +34 95 4691262, e-mail: amontano@cica.es 


\section{Abstract}

14 A ripe olive model system was used to evaluate the potential inhibiting effects on 15 acrylamide formation from a set of amino acids and water-soluble vitamins. The system 16 was based on ripe olive juice heated at $121^{\circ} \mathrm{C}$ for $30 \mathrm{~min}$ in a stainless steel tubular 17 reactor. The most potent acrylamide inhibitors were proline and sarcosine, both with 18 inhibition rates of $\sim 75 \%$ at a $100 \mathrm{mM}$ level. In addition, glycine, ornithine, taurine, and $19 \gamma$-amino butyric acid were effective (50-65\% inhibition) while the rest of the 20 compounds demonstrated weak or non-significant effects. Acrylamide contents in the 21 model system were found to be highly correlated with the corresponding contents in the real product. The kinetic pattern for the formation of acrylamide in the absence and presence of two selected amino acids, added separately or together, was well fitted using a simple logistic function.

26 Keywords: Acrylamide, Amino acids, Food model system, Kinetics, Mitigation,

$27 \quad$ Vitamins 


\section{Introduction}

Acrylamide (AA) has been a focus of attention by the scientific community in recent years. This compound has been classified by the International Agency for Research on Cancer (IARC) as a probable human carcinogen (IARC, 1994). In early 2002, high AA levels were reported in potato products and cereals, such as fried potatoes, baked potatoes, bread, breakfast cereals, and biscuits (Tareke et al., 2002). Subsequent studies confirmed this finding (FDA, 2006) and also reported high AA levels in other products such as ripe olives (Casado and Montaño, 2008). Previous surveys also showed that AA was not detected in the olives of other processing types (e.g. Spanish-style green olives, directly brined olives, etc.), or in other low acid canned vegetables such as asparagus, green beans, and spinach (FDA, 2006). Ripe olives (also called "Californian-style table olives") are one of the most important classes of table olive commercialized in the world. In this type of processing the olives are treated with a series of dilute $\mathrm{NaOH}$ solutions (lye) to remove their natural bitterness, which is caused by glucoside oleuropein. Between lye treatments, the fruits are aerated. During this operation, the fruits are progressively darkened due to polyphenol oxidation. After the lye treatments and oxidation, the olives are washed several times with water to remove most of the residual lye, reaching a final $\mathrm{pH}$ of around 7, and placed in 3-5\% brine with ferrous gluconate or ferrous lactate to maintain their color (Sánchez et al., 2006). Finally, the olives are canned in mild salt brine, and heat sterilized (generally at $\left.121-126^{\circ} \mathrm{C}\right)$.

The use of additives for the potential inhibition of AA formation is a strategy that has been investigated in different foods, including ripe olives. Of the additives tested in this product, only sodium bisulfite was able to totally eliminate AA with a 
negligible repercussion on sensory quality (Casado et al., 2010). However, sodium bisulfite is currently not permitted as an additive in table olives in accordance with European regulation (Commission Regulation (EU) No 1129/2011). Therefore, studies to find other additives to be used by the table olive industry with significant AAreducing effects and without any negative effects are necessary. Amino acids or vitamins are especially attractive because their addition to food may also improve its nutritional value. However, the results previously found with a few amino acids in ripe olives were generally not satisfactory (Casado et al., 2010). Cysteine at $50 \mathrm{mM}$ was demonstrated to be a strong inhibitor of AA formation in ripe olives, but did generate unpleasant off-flavors. In contrast, arginine and methionine at $50 \mathrm{mM}$ had no negative impact on the sensory quality of ripe olives, but their AA-reducing effects were little or negligible. Protein amino acids such as tryptophan, proline, and histidine have demonstrated significant AA-reducing effects in asparagine-glucose model systems (Koutsidis et al., 2009). It has been suggested that these amino acids could form amino acid-AA adducts through Michael addition type reactions thereby reducing the AA content (Friedman and Levin, 2008; Koutsidis et al., 2009). Taurine, a non-protein amino acid, has been reported to be an inhibitor of AA formation in aqueous and potato chip model systems (Shin et al., 2010). Several water-soluble vitamins were reported to significantly inhibit the formation of AA in model systems and in fried potatoes (Zeng et al., 2009; Yuan et al., 2011). Although the action mechanism has not been characterized, the presence of nucleophilic groups, in particular, an amino group in some vitamins, might contribute to their inhibitory activity against AA formation. The reduction of AA levels by using additives may significantly affect the kinetic behavior of acrylamide formation. The kinetics of AA formation have been previously studied in model systems of asparagine and glucose (Claeys et al., 2005; 
79 Knol et al., 2005; Zhang and Zhang, 2008), potato chips (Granda and Moreira, 2005),

80

81

82

83

84 potato crisps (Knol et al., 2009), and potato powder (Franke et al., 2009). Empirical models have been proposed for modeling the formation of AA in foods and model systems (Corradini and Peleg, 2006), In fact, the "Logistic-Fermi" and "LogisticExponential" models have been used to fit the formation of AA in fried potato crisps (Knol et al., 2009) and in an asparagine-glucose model system (Zhang and Zhang, 2008). Using these models that only give a mathematical description of the formation or degradation of AA in food bypasses the problem of considering all the mechanisms that occur during the processing of foods. Besides, AA precursors in olives are still unknown. In the case of ripe olives the AA precursors appear to be different from those in other heated foods. Thus, it is well-demonstrated that the Maillard reaction from amino acids, mainly asparagine, along with reducing sugars, represents the main formation route of AA in potatoes products (Amrein et al., 2004; Taubert et al., 2004), roasted almonds (Amrein et al., 2005) and roasted tea (Mizukami et al., 2006).

However, previous studies in olives showed no correlation between their AA content and any of the sugars or amino acids determined before sterilization, which appears to indicate that these compounds are irrelevant as AA precursors in olives (Amrein et al., 2007; Casado and Montaño, 2008). The aim of the present work was twofold. The first aim was to assess the efficiency of selected amino acids and water-soluble vitamins to eliminate or reduce AA in a ripe olive model system, which mimicked the chemical composition and the heat treatment of ripe olives. For comparison purposes, a strong inhibitor of AA formation in ripe olives, namely sodium sulfite, was also tested. To evaluate the reliability of the model system, some results obtained from the model system were compared with those obtained with the real product. The second aim was 
to investigate the kinetic profile of AA formation in the ripe olive model both in the absence and presence of selected additives.

\section{Materials and methods}

\subsection{Chemicals}

Individual amino acids (L-arginine, glycine, L-tryptophan, L-proline, L-histidine, DL-ornithine hydrochloride, taurine, sarcosine, and $\gamma$-amino- $n$-butyric acid), vitamins (thiamine hydrochloride, VB1; nicotinic acid, VB3; pyridoxine, VB6; biotin, VB7; and sodium- L -ascorbate, VC), and sodium sulfite were supplied by Sigma-Aldrich (St. Louis, MO). Alliin ( $S$-allyl-L-cysteine sulfoxide) was isolated from garlic powder by the method of Mochizuki et al. (1997). The garlic powder was prepared as follows: fresh garlic cloves were frozen in liquid nitrogen, immediately peeled, and lyophilized. Methiin ( $S$-methyl-L-cysteine sulfoxide) was synthesized as described by Shen and Parkin (2000) using S-methyl-L-cysteine (Sigma) as the starting material. Deionized water (Milli-Q; Millipore Corp.) was used throughout. All reagents and chemicals used for the AA analysis were as described by Casado and Montaño (2008). All other chemical and solvents were of analytical grade from various suppliers.

\subsection{Preparation of ripe olive model systems}

$$
\text { Green olives (Hojiblanca cultivar) were stored in } 2.4 \% \text { acetic acid for about }
$$
three months before processing, and were then subjected to darkening as follows: olives $(\approx 22 \mathrm{~kg})$ were treated in a horizontal stainless steel cylindrical container $(0.4 \mathrm{~m}$ 
diameter x $0.7 \mathrm{~m}$ length) with a lye solution of $3 \%$, which progressively penetrated the

flesh until the alkali reached the pit. Next, the lye was removed and the olives were washed with water until the $\mathrm{pH}$ reached 8.0. During lye treatment and washing, air was injected through the bottom of the container. Pressurized air is introduced through 15 spigots ( $0.5 \mathrm{~mm}$ diameter) uniformly located in the bottom of the container so that the oxidation process is uniform. Then, a $0.1 \%$ ferrous gluconate solution with $\mathrm{pH}$ corrected to 4.5 was added to fix the black color (López-López et al., 2009). One portion of ripe olives $(\approx 10 \mathrm{~kg})$ was then subjected to the following operations: pitting, homogenization using a mixer, filtration through cheesecloth, and centrifugation at 20,000g for $20 \mathrm{~min}$. After separation of the oil, the resulting juice was stored at $-30{ }^{\circ} \mathrm{C}$ until the moment of performing the different tests. The selected compounds were added separately to juice in known concentrations. The addition levels of the amino acids were 50, 100, and 200 $\mathrm{mM}$ whereas vitamins were assayed at 25, 50, and $100 \mathrm{mM}$. In all cases, prior to heating, the $\mathrm{pH}$ of the mixture was adjusted to 7 . Heat treatment was performed by placing olive juice $(1 \mathrm{~mL})$ in a custom-made cylindrical stainless steel tubular reactor (internal diameter $0.7 \mathrm{~cm}$, length $3.0 \mathrm{~cm}$ ) having one end closed. The reactor was sealed with a stainless steel tube plug, and then heated in an oil bath at $121 \pm 1^{\circ} \mathrm{C}$ for $30 \mathrm{~min}$. The bath was equipped with a stirrer to ensure a homogeneous temperature in the oil. After heating, the sample was immediately cooled in ice water for 3 min to stop any further reaction and analyzed for its AA content. The temperature profile inside the reactor tube was obtained using a stainless steel temperature probe (Pt100 sensor) coupled to a Crison thermometer model 620/3 (Crison Instruments, Barcelona, Spain). The probe ( $3 \mathrm{~mm}$ diameter) was inserted through the hole of a rubber washer $(14 \mathrm{~mm}$ external diameter, $1 \mathrm{~mm}$ internal diameter, $3 \mathrm{~mm}$ thickness) placed under a nut previously connected to the open end of the reactor. The temperature profile is shown in 
153 Figure 1. The control was treated with the same experimental steps but without 154 additives. All heating experiments were performed in triplicate.

\subsection{Preparation of packed ripe olives}

157

Another portion of ripe olives was packed in "A314" glass bottles (145 g of pitted oliveswith $170 \mathrm{~mL}$ of brine capacity) and covered with brine containing 3\%

$\mathrm{NaCl}, 0.015 \%$ ferrous gluconate, and the corresponding compound $\left(\mathrm{Na}_{2} \mathrm{SO}_{3}\right.$, Pro, Sar, or Gly). Compounds were added to give fixed equilibrium values of 100 and $200 \mathrm{mM}$, except for $\mathrm{Na}_{2} \mathrm{SO}_{3}$, which was added at 10 and $20 \mathrm{mM}$. A control product was prepared using the same brine without additives. If necessary, before the olives were covered, the $\mathrm{pH}$ of the packing brine was adjusted to $6.5-7.0$ by adding $\mathrm{NaOH}$ or $\mathrm{HCl}$. Before sealing, the bottles were filled with hot brine $\left(70^{\circ} \mathrm{C}\right)$. Two bottles from each treatment were heated at $121^{\circ} \mathrm{C}$ for $15 \mathrm{~min}$ in a computer-controlled retort (Steriflow, SAS, Paris, France). Before starting the retort cycle, the bottles were pre-heated at $50{ }^{\circ} \mathrm{C}$ for $10 \mathrm{~min}$. In the heating phase or come-up time of the retort cycle, the water process was heated by steam in the primary circuit of heat exchanger; in the holding phase, temperature $\left(121^{\circ} \mathrm{C}\right)$ and pressure $(2.8$ bar) were stabilized; and finally, in the cooling phase, cold water was injected in the heat exchanger in order to cool down the process water. The cycle period was 55 min. Sterilization treatment was performed in triplicate. After 3 months storage, AA analysis was carried out.

\subsection{Kinetic studies}

Ripe olive juice without (control) and with selected additives at fixed concentrations were heated at $121{ }^{\circ} \mathrm{C}$ in tubular reactors for selected heating times $(5$, 
$15,25,35,45,55$, and $65 \mathrm{~min})$. Although heating times longer than $30 \mathrm{~min}$ are not of practical significance in industrial ripe olive processing, prolonged heating times were included in order to consider a possible degradation step of AA. Each heat treatment was performed at least in duplicate. The obtained data were analyzed using different kinetic models. The Logistic-Fermi model (Eq. 1) proposed by Corradini and Peleg (2006) describes the formation of AA by a logistic function and the degradation by a Fermi-type function:

$C(t)=\left[\frac{a(T)}{1+\exp \left[k_{1}(T)\left[t_{c 1}(T)-t\right]\right\}}-\frac{a(T)}{1+\exp \left[k_{1}(T) t_{c 1}(T)\right]}\right] \cdot \frac{1}{1+\exp \left\{k_{2}(T)\left[t-t_{c 2}(T)\right]\right\}}$

where $C(t)$ is the concentration of AA, $t_{c 1}(T)$ and $t_{c 2}(T)$ are temperature-dependent time characteristics for the inflection points in the formation $\left(t_{c 1}\right)$ and degradation $\left(t_{c 2}\right)$ of AA, $k_{1}(T)$ and $k_{2}(T)$ are temperature-dependent steepness parameters around the inflection points for the formation $\left(k_{1}\right)$ and degradation $\left(k_{2}\right)$ of AA and $a(T)$ serves as a temperature-dependent "scale factor" for the AA concentration.

The Logistic-Exponential model (Eq. 2) differs from the above model in the function that describes the degradation of AA:

$C(t)=\left[\frac{a(T)}{1+\exp \left\{k_{1}(T)\left[t_{c 1}(T)-t\right]\right\}}-\frac{a(T)}{1+\exp \left[k_{1}(T) t_{c 1}(T)\right]}\right] \cdot \exp \left(-\frac{t}{\tau(T)}\right)$

where $\tau(T)$ is a temperature-dependent characteristic of time.

Since AA was apparently not degraded as a result of the applied heat treatments the simple logistic function (Eq. 3) describing the AA formation was also studied:

$$
C(t)=\frac{a(T)}{1+\exp \left\{k_{1}(T)\left[t_{c 1}(T)-t\right]\right\}}
$$


203 Since the $R^{2}$ value cannot be used to evaluate nonlinear models, the quality of fit was

204

205

206

207

208

209

210

211

212

213

214

215

216

217

218

219

220

221

222

223

224

225

expressed as the pseudo- $R^{2}$ value:

$$
\text { pseudo- } R^{2}=1-\left(\mathrm{SS}_{\text {residual }} / \mathrm{SS}_{\text {corrected total }}\right)
$$

where $\mathrm{SS}_{\text {residual }}$ stands for the sum of squares of residuals and $\mathrm{SS}_{\text {corrected total }}$ for the corrected total sum of squares, that is, the squared difference of the observed value from the mean summed over all observations (Motulsky and Christopoulos, 2003).

The adequacy of the kinetic model was also evaluated graphically by plotting the predicted values against the experimental values.

It is known that that the coordinates of the inflexion point $(\mathrm{P})$ of the above logistic function are $\left(t_{c 1}, a / 2\right)$ and the curve's slope (formation rate) at this point satisfies the equation:

$$
\mathrm{dP} / \mathrm{dt}=k_{1} \mathrm{P}(1-\mathrm{P} / a)
$$

Therefore,

\subsection{Analysis of $A A$}

$$
\mathrm{dP} / \mathrm{dt}=k_{1} a / 4
$$

previously (Casado and Montaño, 2008). AA was determined by gas chromatographymass spectrometry (GC-MS) after bromination and ethyl acetate extraction of the 2,3dibromopropionamide using ${ }^{13} \mathrm{C}_{3}$-AA as an internal standard. 


\subsection{Statistical analysis}

228

All experiments were performed in triplicate and statistically analyzed by means of analysis of variance (ANOVA) on a significance level of $p=0.05$. The software Statistica version 7.0 (Statsoft Inc., Tulsa, OK) was used.

\section{Results and discussion}

\subsection{Effect of additives on AA formation in ripe olive model system}

In control juice, $319 \pm 50 \mu \mathrm{g} / \mathrm{L}$ (mean $\pm \mathrm{SD}, \mathrm{n}=3$ ) of $\mathrm{AA}$ was formed after 30

min heating at $121^{\circ} \mathrm{C}$. As expected, sodium sulfite was found to be a very effective AA-

bisulfite (data not shown). After the addition of $20 \mathrm{mM}$ or more, the AA formation was

completely inhibited, which confirmed the effectiveness of bisulfite as a strong inhibitor of AA formation in ripe olives as previously reported by Casado et al. (2010).

Of the tested protein amino acids (Figure 2), proline was the most potent inhibitor of

AA formation (reduction rates of $61 \%, 78 \%$, and $91 \%$ at $50 \mathrm{mM}, 100 \mathrm{mM}$, and 200 $\mathrm{mM}$, respectively) followed by glycine (30\%, 54\%, and 64\%). Tryptophan inhibited AA formation ( $\sim 36 \%$ reduction), but reduction was not dose-dependent. Arginine reduced the formation of AA at concentrations of 100 and $200 \mathrm{mM}$ (reductions of $24 \%$ and $42 \%$, respectively), but it was not effective at the $50 \mathrm{mM}$ level. Finally, histidine was only effective at the highest concentration assayed (39\% reduction at $200 \mathrm{mM})$. It has been demonstrated that the above-mentioned amino acids can form amino acid-AA adducts 
through Michael addition type reactions thereby reducing the AA content, although a clear identification in the specific condensation product was not obtained in the case of arginine (Koutsidis et al., 2009; Adams et al., 2010).

Of the non-protein amino acids, sarcosine ( $N$-methyl glycine) showed the highest inhibition rates, similar to those of proline (Figure 3). The higher reactivity of sarcosine in comparison with the corresponding primary amine containing amino acid (i.e. glycine) is noteworthy. Ornithine, taurine, and $\gamma$-amino- $n$ - butyric acid also gave good inhibition rates (50-65\% at $100 \mathrm{mM})$. Shin et al. (2010) reported significant reductions of AA formation in a fried potato chip model when, prior to frying at $170{ }^{\circ} \mathrm{C}$ for $3 \mathrm{~min}$, the potato slices were soaked in $0.1-2 \%$ taurine solution for $30 \mathrm{~min}$.

However, to our best of knowledge, the potential use of other nonprotein amino acids such as sarcosine, ornithine and $\gamma$-amino- $n$ - butyric acid to decrease AA formation in processed foods has not been previously suggested. In addition, all these nonprotein amino acids could be particularly interesting from a healthy standpoint, as they are widely used as components in nutritional supplements.

Natural compounds are attractive candidates to be added as inhibitors of AA formation in processed foods. In the present study, the non-protein sulfur-containing amino acids alliin and methiin were tested at concentrations between $25-100 \mathrm{mM}$ (Figure 3). These two $S$-alk(en)yl-L-cysteine sulfoxides are present in relatively high concentrations in Allium vegetables (Horie and Yamashita, 2006) and they are thought to be beneficial to health. Unfortunately, alliin did not show a significant AA-reducing effect compared to the control juice in any case while methiin only reduced AA formation at high concentrations with reduction rates rather modest $(<40 \%)$. Moreover, as a serious drawback, a distinct "garlic odor" after the heat treatment was noted in all samples with added alliin or methiin. This odor can be attributed to thermal breakdown 
products of these compounds (Kubec et al., 1997; Kubec et al., 1998). In our previous study (Casado et al., 2010), the addition of minced blanched garlic at $15 \mathrm{~g} / \mathrm{kg}$ of ripe olives was reported to reduce the AA content in ripe olives by $23 \%$, which was hypothesized to be due to the presence of the cysteine sulfoxides in garlic, mainly alliin. The above-mentioned amount of blanched garlic would correspond to alliin and methiin concentrations of $\sim 1 \mathrm{mM}$ and $\sim 0.1 \mathrm{mM}$, respectively, assuming that the levels of these compounds in garlic are 35 and $3.5 \mathrm{mg} / \mathrm{g}$ of dm, respectively, and there are no losses during the blanching treatment (Montaño et al. 2011; Beato et al., 2012). These concentrations are 1-3 orders of magnitude lower than the concentrations tested in the systems (Zeng et al., 2009; Yuan et al., 2011). present study. Therefore, the above results appear not to confirm the hypothesis that cysteine sulfoxides are involved in the AA reducing effect of blanched garlic, suggesting that other unknown compounds would be responsible for this effect. It has been reported that allicin (diallylthiosulfinate), which is formed from alliin by the action of the enzyme alliinase when raw garlic is minced, effectively reduces AA formation ( $>50 \%$ reduction) in an asparagine/fructose model system containing $0.0375 \%$ allicin (Yuan et al., 2011). However, allicin is expected not to be present in blanched garlic, as blanching treatment results in the deactivation of alliinase (Rejano et al., 2004). Of the tested water-soluble vitamins, only VB1 significantly reduced the AA content compared to the control juice (Figure 4). However, the addition of this vitamin imparted a noticeable bad odor to heated juice. Presumably, this could be related to the presence of a thiazole ring as a component of the VB1 molecule. The other watersoluble vitamins had no significant AA-reducing effect in the olive model system in general, which is in contrast with the significant AA reductions reported in other model 
Results obtained for a few additives in the model system were compared with those obtained for the same additives in the real product (packed ripe olives). AA formed in the latter product without additives was $598 \mu \mathrm{g} / \mathrm{kg}$ in olive pulp. A good correlation $\left(R^{2}=0.941\right)$ between the AA contents obtained in the model system and those obtained in the real product was found (Figure 5), with a slope \pm SE of $1.72 \pm 0.14$.

The reason for the higher AA contents in packed olives compared to model system could be related to the amount of AA precursors in each case. The model system based on olive juice is a simplified representation of the real product (packed olives).

Recently, we have demonstrated that peptides and/or proteins are precursors of AA olive juice (which more properly should be called olive water, i.e. the aqueous fraction of olive pulp) but also in the solid fraction linked to olive components (eg., fiber) and even in the olive oil (Hidalgo et al., 2001). Therefore, the amount of AA precursors in packed olives should be higher than in olive juice, which would explain the higher AA contents in packed olives.

The above correlation between the model system and the real product indicates that one could use the ripe olive model system as a simple and reliable tool for screening compounds with potential inhibitor effects on the AA formation in ripe olive processing. However, the obtained linear function could not be applicable under different conditions with respect to those used in the present study (i.e. olive juice and real product made with Hojiblanca olives processed by using the same darkening method). Changes in the darkening method or olive cultivar could affect the kinetic behavior of AA formation, which in turn would affect the final AA level in ripe olives (Casado and Montaño, 2008). 
The kinetic profile of AA formation in the ripe olive model at $121{ }^{\circ} \mathrm{C}$ for $5-65$ min in the absence (control) and presence of selected additives is shown in Figure 6. The additives selected were sarcosine at $100 \mathrm{mM}$ and arginine at $200 \mathrm{mM}$, which are examples of amino acids with strong and weak capacities, respectively, to inhibit AA formation. After a "lag-phase" of at least $5 \mathrm{~min}$, in which AA formation was negligible, AA content increased and eventually reached an equilibrium value. This "lag-phase" was expected taking into account that AA formation in foods appears to begin at temperatures around $120^{\circ} \mathrm{C}$ (Stadler et al., 2002) and this temperature inside the tubular reactor was just reached after 10 min heating (Figure 1). When the "Logistic-Fermi" and "Logistic-Exponetial" models were applied, the fit of these empirical models to our data did not give satisfactory results in any case (data not shown), which was probably due to the absence of a degradation step of AA and the relatively low number of data points. However, when a simple logistic pattern based on only three parameters was used (Eq. 3), the fit was quite good for the data set measured (Figure 6). Calculation results of the kinetic parameters describing the formation of AA in each case along with the corresponding pseudo- $R^{2}$ values are shown in Table 1 . The goodness of fit of the model on the data was confirmed graphically by the scatter plots shown in Figure 7, where a high correlation was found between predicted and experimental values in all cases. The parameters $k_{1}$ and $t_{\mathrm{c} 1}$ in the juices with additives were not significantly different compared to the control. In other words, the addition of the amino acids to the model system did not appear to influence the nature of the kinetic model. Nevertheless, the parameter $a$ was significantly lower in the additive-containing samples compared to the control. A consistently lower $a$ value indicates a lower level of AA production. This 
means that sarcosine and arginine at the concentrations tested had a significant antagonist effect on the AA formation at $121^{\circ} \mathrm{C}$. When a mixture of $100 \mathrm{mM} \mathrm{Sar}+200$ mM Arg was tested, the calculated parameter $a$ was significantly lower than those obtained for the amino acids separately, but again $k_{1}$ and $t_{\mathrm{c} 1}$ did not significantly change. This result demonstrates that the AA reducing effect of the above mixture was significantly higher than the two amino acids added separately. It must be stressed that the parameter $k_{1}$ does not actually represent a formation rate, but this can be calculated from the curve's slope at the inflexion point according to equation 6 . The obtained values of the formation rate (Table 1) were consistent with the differences observed in the AA formation curves (Figure 6) where control system showed a much faster formation compared to the systems with AA inhibitors.

The logistic model (or empirical models in general) as mentioned above only describe the AA formation kinetics but they do not give much insight into the mechanism behind the AA formation. A logistic function was previously used by Granda and Moreira (2005) to model the kinetics of AA formation in traditional fried potato chips. Knol et al. (2009) used the "Logistic- Exponential" model to make predictions for the AA formation in potato crisps based on the strong correlation between the parameter $a$ obtained by the model and the reducing sugar content. Since AA precursors in olives are still unknown, a similar correlation between the parameter $a$ derived from the logistic function and the content of AA precursor cannot be determined as yet. Studies are in progress which use the tubular reactor methodology described in this work to identify the main AA precursors in olives. Once these studies are carried out and assuming that a good correlation between parameter $a$ and precursor content is found, the next step would be to investigate the kinetics of AA formation in real food (i.e. ripe olives), under well-controlled conditions, and to apply the logistic 
376 function to kinetic data. Models of the proposed kind might be used to simulate and

377 predict the generation of AA in ripe olives. In addition, the obtained information might

378 be useful for developing new strategies for the reduction or elimination of AA by

379 decreasing or eliminating precursors.

380

\section{Conclusion}

382

The present study shows that our olive model system is a simple and reliable

tool for the screening of additives as potential AA inhibitors in ripe olive processing.

Excluding sulfite, the compounds which had the highest impact on the AA level were

proline and sarcosine. Further research is currently underway to determine whether

these compounds would be good candidates to decrease AA formation in ripe olive processing taking into account their impact on the sensory characteristics of the product.

The ripe olive model system was useful in identifying the kinetics of AA formation at

$121{ }^{\circ} \mathrm{C}$. This was modeled using a simple logistic model, characterized by an increase in the AA content with heating time until an equilibrium value is eventually reached.

Hopefully, this type of model could be used in the future to predict the formation of AA and to develop new strategies for its reduction or elimination in ripe olives.

\section{Acknowledgements}

This study was supported in part by the European Union (FEDER funds) and the Spanish government through Project AGL 2010-19178. Financial support from the Junta de Andalucía (group AGR-208) is also acknowledged. 


\section{References}

402

403

404

405

406

407

408

409

410

411

412

413

414

415

416

417

418

419

Adams, A., Hamdani, S., Van Lancker, F., Méjri, S., \& De Kimpe, N. (2010). Stability of acrylamide in model systems and its reactivity with selected nucleophiles. Food Research International, 43, 1517-1522.

Amrein, T. M., Schiónbochler, B., Rohner, F., Lukac, H., Schneider, H., Keiser, A., Escher, F., \& Amadó, R. (2004). Potential for acrylamide formation in potatoes: data from the 2003 harvest. European Food Research and Technology, 219, $572-578$.

Amrein, T.M., Lukac, H., Andres, L., Perren, R., Escher, F., \& Amadò, R. (2005). Acrylamide in roasted almonds and hazelnuts. Journal of Agricultural and Food Chemistry, 53, 7819-7825.

Amrein, T. M., Andres, L., Escher, F., \& Amadó, R. (2007). Occurrence of acrylamide in selected foods and mitigation options. Food Additives and Contaminants, 24, $13-25$.

Beato, V.M., Sánchez, A.H., de Castro, A., \& Montaño, A. (2012). Effect of processing and storage time on the contents of organosulfur compounds in pickled blanched garlic. Journal of Agricultural and Food Chemistry, 60, 3485-3491.

Casado, F. J. \& Montaño, A. (2008). Influence of processing conditions on acrylamide content in black ripe olives. Journal of Agricultural and Food Chemistry, 56, 2021-2027.

Casado, F. J., Sánchez, A. H., \& Montaño, A. (2010). Reduction of acrylamide content of ripe olives by selected additives. Food Chemistry, 119, 161-166. 
Casado, F.J., Montaño, A., Spitzner, D., \& Carle, R. (2013). Investigations into acrylamide precursors in sterilized table olives: Evidence of a peptic fraction being responsible for acrylamide formation. Food Chemistry, 141, 1158-1165.

Claeys, W.L., de Vleeschouwer, K., \& Hendrickx, M.E. (2005). Kinetics of acrylamide formation and elimination during heating of an asparagine-sugar model system. Journal of Agricultural and Food Chemistry, 53, 9999-10005.

Commission Regulation (EU) No 1129/2011 of 11 November 2011 amending Annex II to Regulation (EC) No 1333/2008 of the European Parliament and of the Council by establishing a Union list of food additives. Official Journal of the European Union L 295, 1-177.

Corradini, M.G., \& Peleg, M. (2006). Linear and non-linear kinetics in the synthesis and degradation of acrylamide in foods and model systems. Critical Reviews in Food Science and Nutrition, 46, 489-517.

FDA (US Food and Drug Administration). Survey Data on Acrylamide in Food: Individual Food Products. Center for Food Safety and Nutrition, 2006; available online at http://www.fda.gov/Food/FoodSafety/FoodContaminantsAdulteration/Chemical Contaminants/Acrylamide/ucm053549.htm.

Franke, K., Strijowski, U., \& Reimerdes, E.H. (2009). Kinetics of acrylamide formation in potato powder. Journal of Food Engineering, 90, 135-140.

Friedman, M., \& Levin, C.E. (2008). Review of methods for the reduction of dietary content and toxicity of acrylamide. Journal of Agricultural and Food Chemistry, $56,6113-6140$. 
Granda, C., \& Moreira, R.G. (2005). Kinetics of acrylamide formation during traditional and vacuum frying of potato chips. Journal of Food Process Engineering, 28, 478-493.

Hidalgo, F.J., Alaiz, M., \& Zamora, R. (2001). Determination of peptides and proteins in fats and oils. Analytical Chemistry, 73, 698-702.

Horie, H., \& Yamashita, K. (2006). Non-derivatized analysis of methiin and alliin in vegetables by capillary electrophoresis. Journal of Chromatography A, 1132, 337-339.

IARC. (1994). Some industrial chemicals (pp 435-53). Lyon: IARC. [IARC Monographs on the evaluation for carcinogenic risk of chemicals to humans, Vol. 60].

Knol, J.J., van Loon, W.A.M., Linssen, J.P.H., Ruck, A.-L., van Boekel, M.A.J. S., \& Voragen, A.G.J. (2005). Toward a kinetic model for acrylamide formation in a glucose-asparagine reaction system. Journal of Agricultural and Food Chemistry, 53, 6133-6139.

Knol, J.J., Kiklund, G.A.I., Linssen, J.P.H., Sjöholm, I.M., Skog, K.I., \& van Boekel, M.A.J.S. (2009). Kinetic modeling: a tool to predict the formation of acrylamide in potato crisps. Food Chemistry, 113, 103-109.

Koutsidis, G., Simons, S.P.J., Thong, Y.H., Haldoupis, Y., Mojica-Lazaro, J., Wedzicha, B.L., \& Mottram, D.S. (2009). Investigations on the effect of amino acids on acrylamide, pyrazines, and Michael addition products in model systems. Journal of Agricultural and Food Chemistry, 57, 9011-9015. 
Kubec, R., Velísek, J., Dolezal, M., \& Kubelka, V. (1997). Sulfur-containing volatiles arising by thermal degradation of alliin and deoxyalliin. Journal of Agricultural and Food Chemistry, 45, 3580-3585.

Kubec, R., Drhová, V., \& Velísek, J. (1998). Thermal degradation of S-methylcysteine and its sulfoxide-important flavor precursors of Brassica and Allium vegetables. Journal of Agricultural and Food Chemistry, 46, 4334-4340.

López-López, A., Rodriguez-Gómez, F., Cortés-Delgado, A., Montaño, A., \& GarridoFernández, A. (2009). Influence of ripe table olive processing on oil characteristics and composition as determined by chemometrics. Journal of Agricultural and Food Chemistry, 57, 8973-8981.

Mizukami, Y., Kohata, K., Yamaguchi, Y., Hayashi, N., Sawai, Y., Chuda, Y., Ono, H., Yada, H., \& Yoshida, M. (2006). Analysis of acrylamide in green tea by gas chromatography-mass spectrometry. Journal of Agricultural and Food Chemistry, 54, 7370-7377.

Mochizuki, E., Yamamoto, T., Horie, M., Ikai, Y., \& Nakazawa, H. (1997). Simultaneous determination of alliin and allicin in Allium plants and their products by liquid chromatography. Journal of AOAC International, 80, 10521056.Montaño, A., Beato, V.M., Mansilla, F., \& Orgaz, F. (2011). Effect of genetic characteristics and environmental factor son organosulfur compounds in garlic (Allium sativum L.) grown in Andalusia, Spain. Journal of Agricultural and Food Chemistry, 59, 1301-1307.

Motulsky, H.J., \& Cristopoulos, A. (2003). Fitting models to biological data using linear and nonlinear regression. A practical guide to curve fitting. GraphPad software Inc., San Diego, CA. http://www.graphpad.com/manuals/prism4/regressionbook.pdf 
Rejano, L., de Castro, A., Sánchez, A.H., Casado, F.J., \& Montaño, A. (2004). Thermal kinetics of pungency loss in relation to the quality of pickled garlic. International Journal of Food Science and Technology, 39, 311-317.

Sánchez, A.H., García, P., \& Rejano, L. (2006). Elaboration of table olives. Grasas y Aceites, 57, 86-94.

Shen, C., \& Parkin, K.L. (2000). In vitro biogeneration of pure thiosulfinates and propanethial-S-oxide. Journal of Agricultural and Food Chemistry, 48, 62546260.

Shin, D.C., Kim, C.T., Lee, Y.C., Choi, W.J., Na, Y.J., \& Lee, K.W. (2010). Reduction of acrylamide by taurine in aqueous and potato chip model systems. Food Research International, 43, 1356-1360.

Stadler, R.H., Blank, I., Varga, N., Robert, F., Hau, J., Guy, P.A., Robert, M.-C., \& Riediker, S. (2002). Acrylamide from Maillard reaction products. Nature, 419, 449.

Tareke, E., Rydberg, P., Karlsson, P., Eriksson, S., \& Törnqvist, M. (2002). Analysis of acrylamide, a carcinogen formed in heated foodstuffs. Journal of Agricultural and Food Chemistry, 50, 4998-5006.

Taubert, D., Halfinger, S., Henkes, L., Berkels, R., \& Schöming, E. (2004). Influence of processing parameters on acrylamide formation during frying of potatoes. Journal of Agricultural and Food Chemistry, 52, 2735-2739.

Yuan, Y., Shu, C., Zhou, B., Qi, X., \& Xiang, J. (2011). Impact of selected additives on acrylamide formation in asparagine/sugar Maillard model systems. Food Research International, 44, 449-455. 
520 Zeng, X., Cheng, K.-W., Jiang, Y., Lin, Z.-X., Shi, J.-J., Ou, S.-Y., Chen, F., \& Wang, M. (2009). Inhibition of acrylamide formation by vitamins in model reactions and fried potato strips. Food Chemistry, 116, 34-39.

523 Zhang, Y., \& Zhang, Y. (2008). Effect of natural antioxidants on kinetic behaviour of acrlamide formation and elimination in low-moisture asparagine-glucose model system. Journal of Food Engineering, 85, 105-115.

526 
529 Figure 1. Temperature-time profile of samples heated in a custom-made cylindrical 530 stainless steel tubular reactor (internal diameter $0.7 \mathrm{~cm}$, length $3.0 \mathrm{~cm}$ ).

531 Figure 2. Dose-response effect of selected protein amino acids on the acrylamide 532 inhibition (percentage from control) in a ripe olive model system. Data values are mean $533 \pm \mathrm{SD}(\mathrm{n}=3)$. Bars with an asterisk indicate significant difference from the control 534 ( $\mathrm{p}<0.05)$. Abbreviations: Pro = proline, Gly = glycine, $\operatorname{Trp}=$ tryptophan, $\operatorname{Arg}=$ 535 arginine, and $\mathrm{His}=$ histidine.

536 Figure 3. Dose-response effect of selected non-protein amino acids on the acrylamide

537 inhibition (percentage from control) in a ripe olive model system. Data values are mean $538 \pm \mathrm{SD}(\mathrm{n}=3)$. Bars with an asterisk indicate significant difference from the control 539 ( $\mathrm{p}<0.05)$. Abbreviations: Sar $=$ sarcosine, Orn $=$ ornithine, Tau $=$ taurine, and $540 \quad \mathrm{GABA}=\gamma$-aminobutyric acid.

541 Figure 4. Dose-response effect of selected water-soluble vitamins on the acrylamide 542 inhibition (percentage from control) in a ripe olive model system. Data values are mean $543 \pm \mathrm{SD}(\mathrm{n}=3)$. Bars with an asterisk indicate significant difference from the control 544 ( $<<0.05)$. Abbreviations: VB1 = thiamine hydrochloride, VB3 = nicotinic acid, $545 \mathrm{VB} 6=$ pyridoxine, $\mathrm{VB7}=$ biotin, and VC $=$ sodium $-\mathrm{L}-$ ascorbate.

546 Figure 5. Relationship between the acrylamide contents in ripe olive model system and 547 those in real product (ripe olives).

548 Figure 6 . Formation of acrylamide as function of heating time at $121^{\circ} \mathrm{C}$ in ripe olive model system in the absence (control) and presence of two different acrylamide 
550 inhibitors. The lines represent acrylamide predicted by the kinetic model (logistic

551 function with three parameters).

552 Figure 7. Plots of experimentally determined acrylamide levels and acrylamide levels

553 predicted by the kinetic model (logistic function with three parameters) in ripe olive

554 model system in the absence (control) and presence of two different acrylamide

555 inhibitors. 
Table 1. Effect of additives on the kinetic parameters describing the formation of acrylamide fitted by logistic function (Eq. 3 in text)

\begin{tabular}{|c|c|c|c|c|c|}
\hline & \multicolumn{5}{|c|}{ Logistic model $^{a}$} \\
\hline Sample & $a(\mu \mathrm{g} / \mathrm{L})$ & $k_{1}\left(\min ^{-1}\right)$ & $t_{\mathrm{c} 1}(\min )$ & Rate $^{b}$ & pseudo- $R^{2}$ \\
\hline Control & $624 \pm 43 a$ & $0.09 \pm 0.02 \mathrm{a}$ & $29 \pm 3 a$ & 13.55 & 0.9590 \\
\hline$+100 \mathrm{mM}$ Sar (1) & $196 \pm 8 c$ & $0.12 \pm 0.02 \mathrm{a}$ & $22 \pm 2 a$ & 6.14 & 0.9714 \\
\hline$+200 \mathrm{mM}$ Arg (2) & $257 \pm 13 b$ & $0.14 \pm 0.03 \mathrm{a}$ & $26 \pm 2 a$ & 8.75 & 0.9454 \\
\hline$(1)+(2)$ & $134 \pm 5 d$ & $0.20 \pm 0.05 a$ & $20 \pm 1 a$ & 6.68 & 0.9341 \\
\hline \multicolumn{6}{|c|}{$\begin{array}{l}{ }^{a} \text { Parameters are expressed as mean } \pm \text { SE. Values of the same parameter with different letters } \\
\text { are significantly different based on } 95 \% \text { confidence intervals. }{ }^{b} \text { Curve's slope at the inflexion } \\
\text { point (equation } 6 \text { in text). }\end{array}$} \\
\hline
\end{tabular}




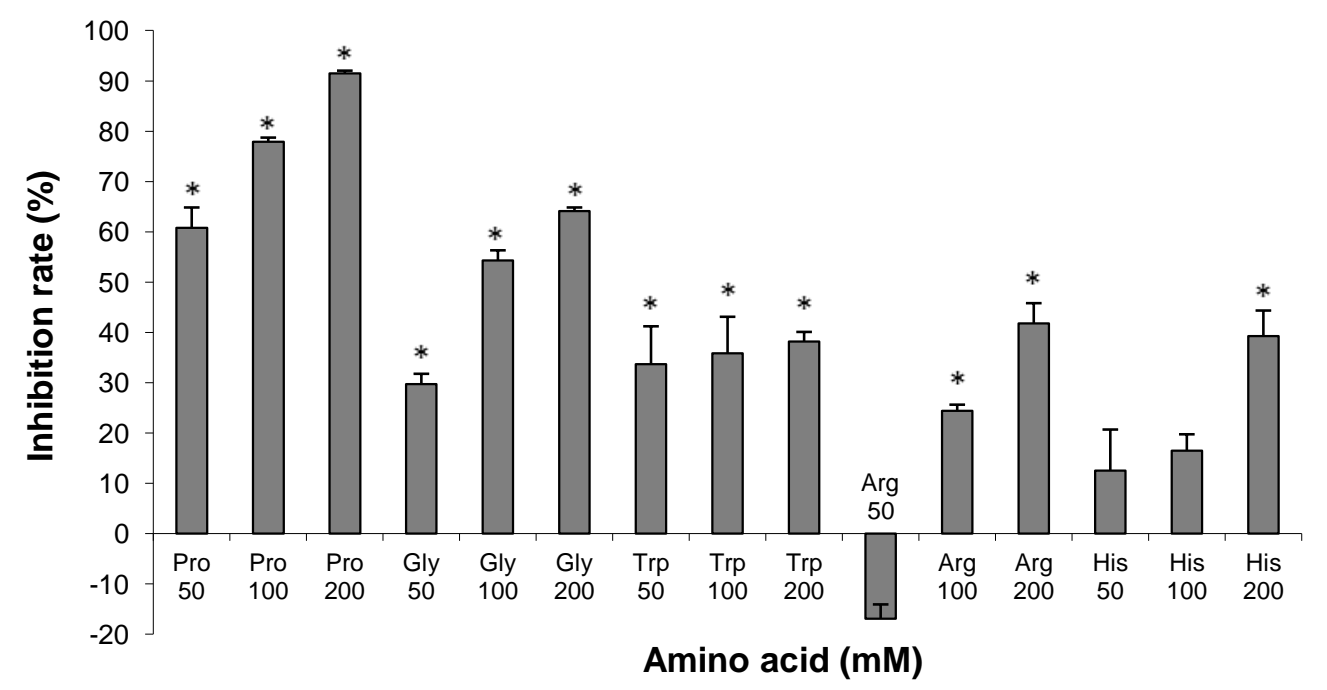




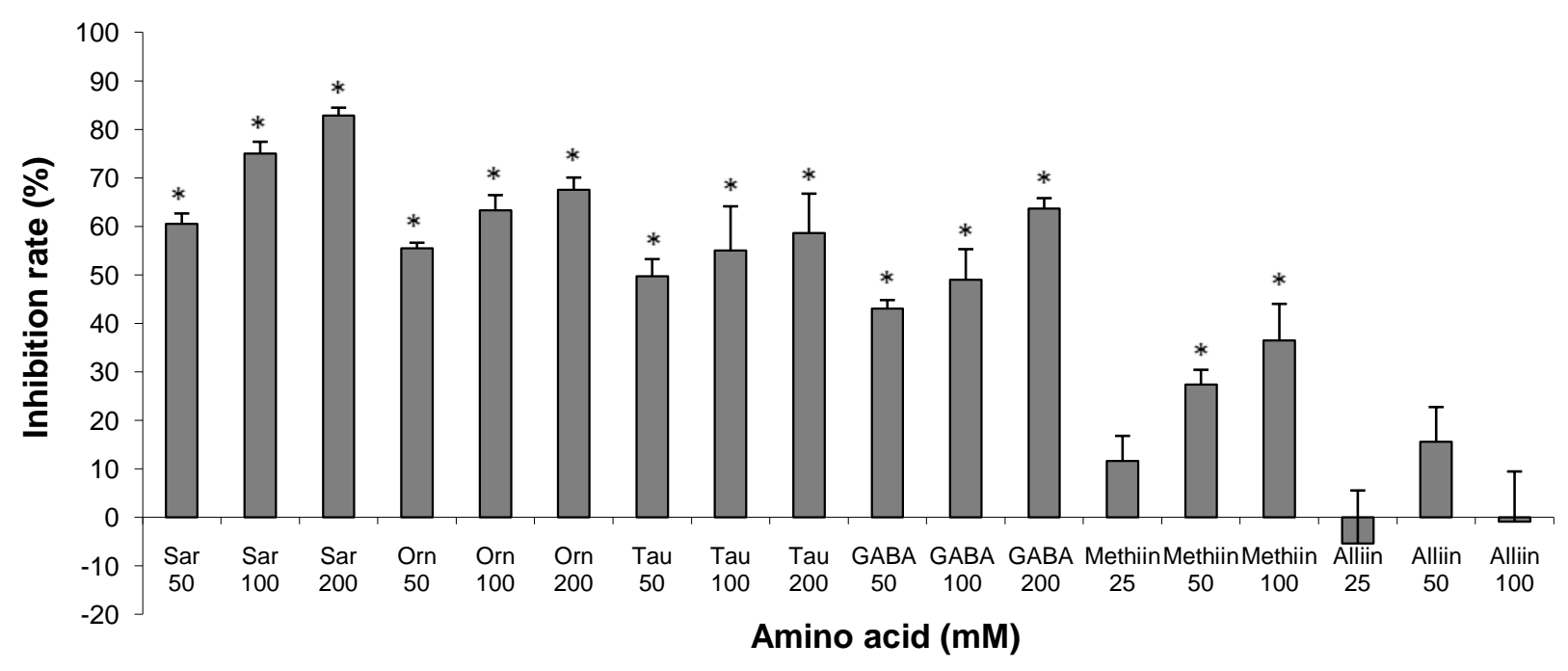




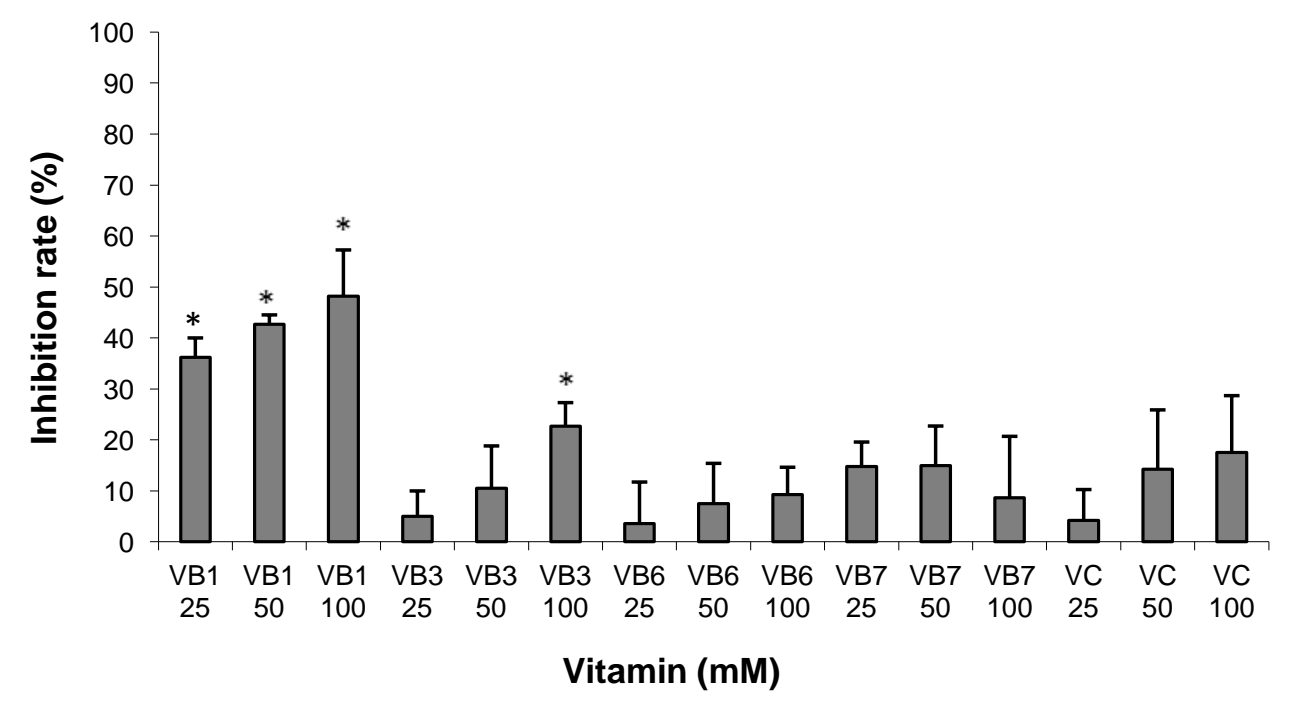


Figure 5

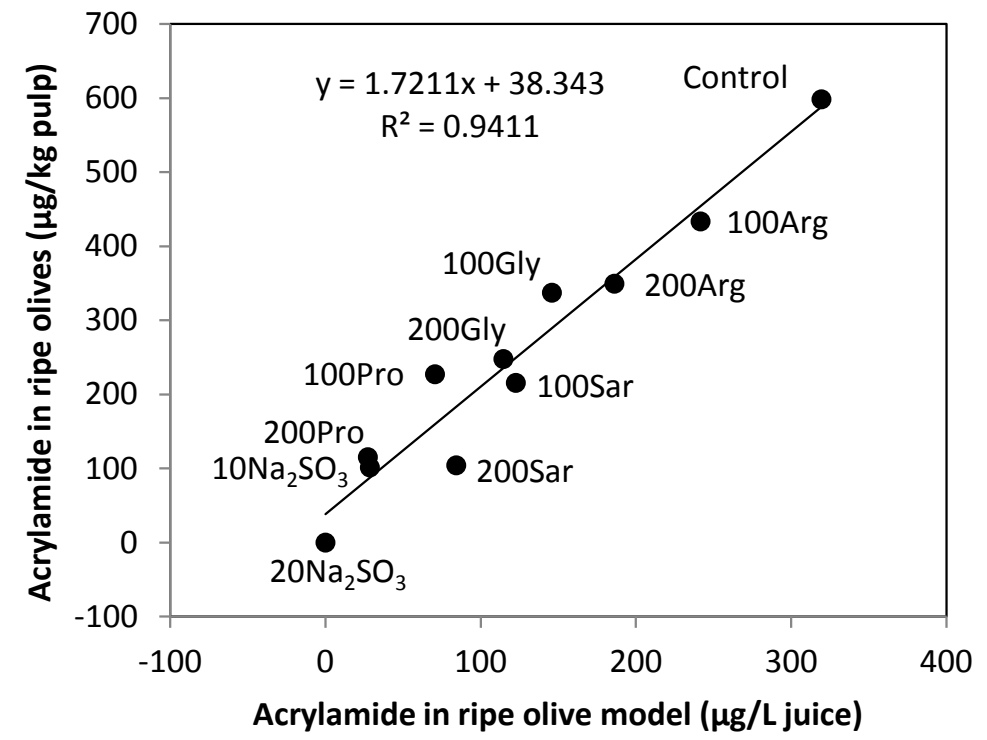



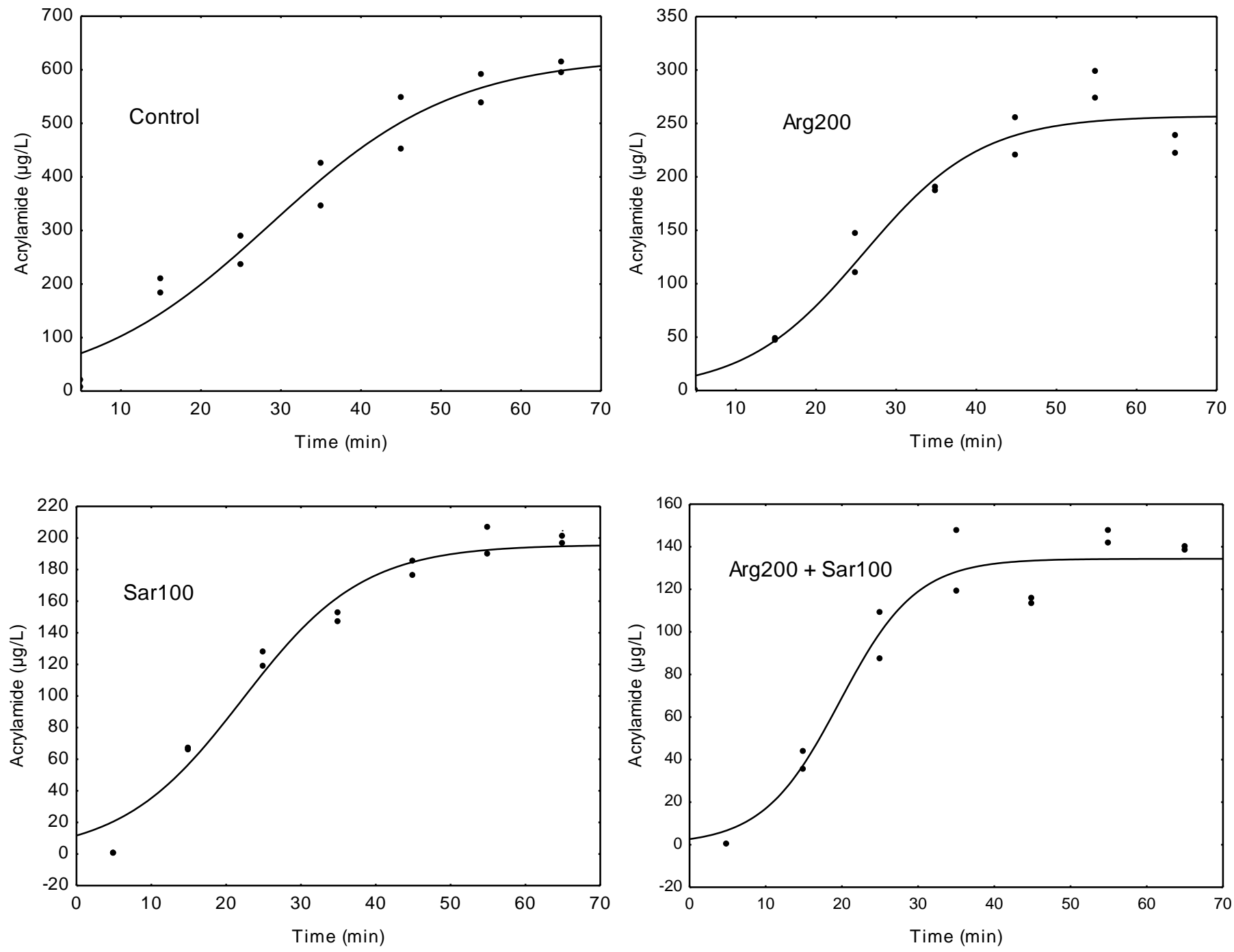

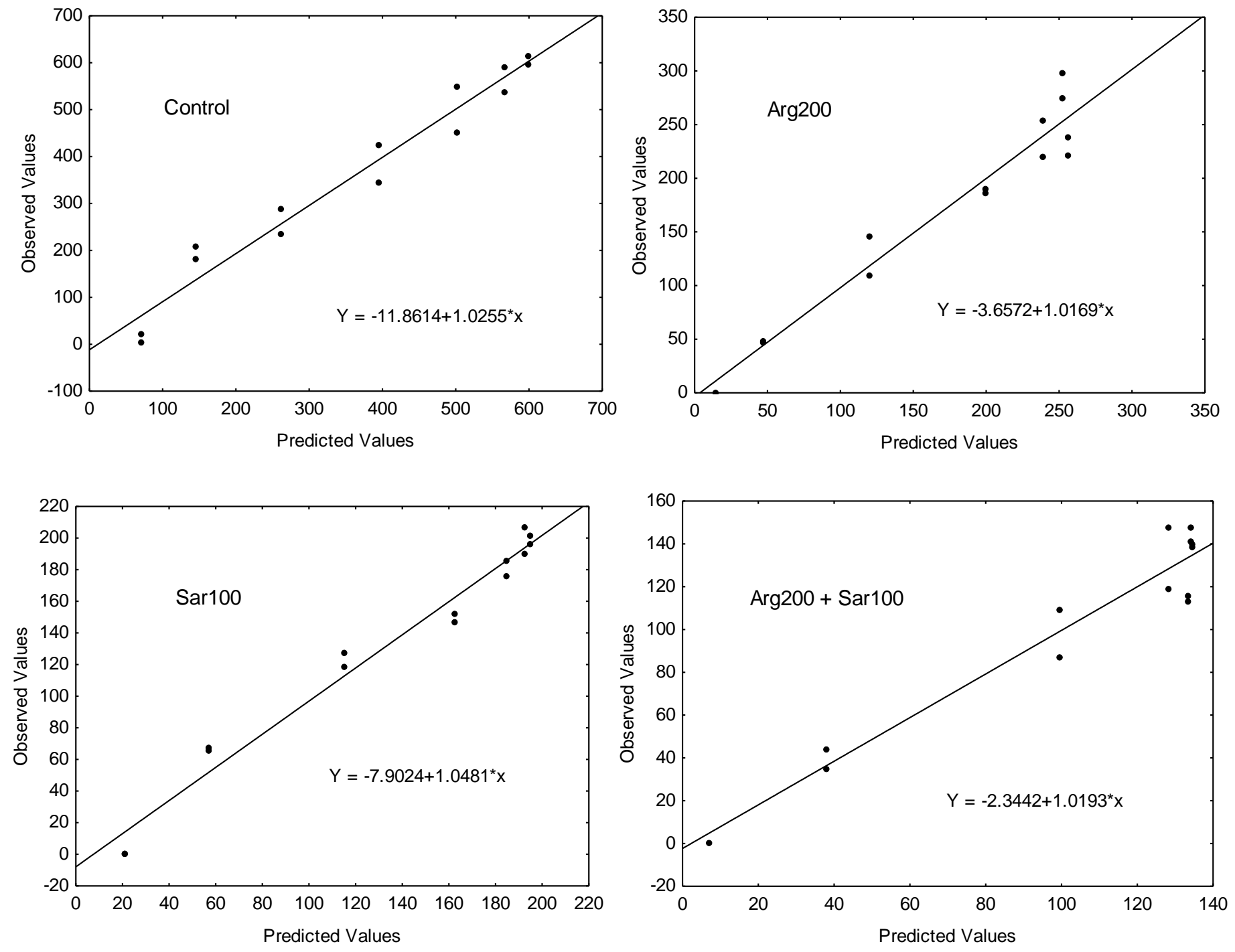